\title{
ANALISIS PERBANDINGAN BIAYA MINE DEWATERING DENGAN METODE LOAD AND HAUL DAN METODE MUD PUMPING PADA ANNUAL PLAN PT ABC
}

\section{COMPARATIVE ANALYSIS OF MINE DEWATERING COST WITH LOAD AND HAUL METHOD AND MUD PUMPING METHOD IN ANNUAL PLAN PT ABC}

\author{
Tri Dedi Gunawan ${ }^{1)}$, Risnal Affandi Zega ${ }^{2)}$, Annisa Primalia ${ }^{3)}$ \\ Corresponding Author E-mail: tridedigunawan@gmail.com
}

\begin{abstract}
Coal is an abundant natural resource in Indonesia and is an alternative energy source that is currently highly developed. Coal mining activities have a positive impact on the economic development of the surrounding area. However, coal mining activities also have a large impact on the environment, especially in mining with the open pit method. One of the big problems in mining activities using the open pit method is the handling of water and mud carried by runoff water from rainwater or ground water. Especially at PT ABC on sump pit Z has a large actual mud volume, which is $147,412 \mathrm{~m}^{3}$ with a large catchment area of $1.99 \mathrm{~km}^{2}$ in June 2020 . The height difference between Sump Pit Z and the processing pond on EOY 2020 is $132 \mathrm{~m}$, so 1 mud pump with 2 booster are needed to pump mud from Sump to the sediment pond. With the actual SG sump being 1.4 and total head on EOY 2020 is $132 \mathrm{~m}$,, a slurry pump with specifications is needed that is capable of pumping water that approaches the actual SG. Using a Dragflow HY85-160B pump and 2 Medso 150 booster pumps, $148.800 \mathrm{~m}^{3}$ per month can be pumped into the treatment pond, with a total cost incurred if using the mud pumping method is $\$ 842.403$. This cost is smaller compared to the costs required for the load and haul method with saving cost up to $57 \%$.
\end{abstract}

Keywords: Coal mining, runoff water, pumps, mud, load and haul

\begin{abstract}
Abstrak: Batubara adalah sumberdaya alam yang melimpah di Indonesia dan menjadi sumber energi alternatif yang saat ini sangat berkembang. Kegiatan penambangan batubara memiliki dampak positif bagi perkembangan ekonomi daerah sekitarnya. Namun kegiatan penambangan batubara juga memiliki dampak yang besar terhadap lingkungan, khususnya pada penambangan dengan metode open pit. Salah satu permasalahan besar dari kegiatan penambangan dengan metode open pit adalah penanganan air dan lumpur oleh air limpasan hujan maupun air tanah. Khususnya di PT ABC pada sump pit Z memiliki volume lumpur aktual yang besar, yaitu 147,412 $\mathrm{m}^{3}$ dengan luas area tangkapan hujan sebesar 1,99 $\mathrm{km}^{2}$ pada bulan Juni 2020. Perbedaan ketinggian antara Sump Pit Z dengan kolam pengolahan hingga akhir tahun 2020 adalah 132 m sehingga dibutuhkan 1 pompa lumpur ditambah 2 booster untuk memompa lumpur dari sump hingga ke kolam pengendapan. Dengan SG aktual sump adalah 1,4 dan head hingga akhir tahun 132 m, maka dibutuhkan pompa lumpur dengan spesifikasi yang sesuai yaitu menggunakan pompa Dragflow HY85-160B dan 2 booster pump Medso 150. Kapasitas pemompaan per bulan adalah 148,800 $\mathrm{m}^{3}$ dengan total biaya sebesar $\$$ 842,403 . Biaya ini lebih rendah jika dibandingkan terhadap total biaya yang dibutuhkan jika menggunakan metode load and haul dengan penghematan mencapai $57 \%$.

Kata kunci: Penambangan batubara, air limpasan, pompa, lumpur, load and haul
\end{abstract}

\section{PENDAHULUAN}

\subsection{Latar Belakang}

Sumberdaya energi yang banyak dimanfaatkan saat ini adalah batubara. Batubara merupakan salah satu sumberdaya alam yang melimpah di Indonesia. Berdasarkan RUEN 2014, ditentukan bahwa batubara akan digunakan sebagai beban dasar untuk memenuhi kebutuhan energi selain gas dan minyak. Dengan adanya kebijakan ini akan memberi dampak positif pada industri pertambangan dan bagi negara.

Salah satu dampak positif kegiatan pertambangan adalah meningkatkan pendapatan dari daerah di sekitarnya serta meningkatkan ekonomi daerah. Dampak negatif yang dihasilkan oleh adanya kegiatan pertambangan yang dilakukan di bentangan alam adalah merusak alam itu sendiri.

Akibat terjadinya perubahan bentangan alam akibat kegiatan pertambangan, banyak 
faktor-faktor lingkungan yang perlu diperhatikan. Faktor penting yang sangat berpengaruh terhadap proses penambangan adalah masalah penanganan air atau yang lebih umum disebut penyaliran tambang.

Kegiatan penambangan yang dilakukan di PT ABC ini dilakukan dengan metode open pit. Penambangan dengan metode open pit akan menyebabkan terbentuknya cekungan pada permukaan tanah dan menjadi tempat terkumpulnya air akibat air hujan maupun air limpasan dari kontur topografi permukaan. Limpasan air yang melalui kontur permukaan tanah membawa material yang dilaluinya yang kemudian terendapkan di titik terdalam.

Penumpukan material ini kemudian menjadi tumpukan lumpur di dasar sump yang perlu untuk dibuang agar kegiatan penambangan dapat terus dilakukan. Kegiatan pengeringan lumpur pada sump dapat dilakukan degan beberapa metode. Beberapa diantaranya adalah dengan metode load and haul dan metode mud pumping.l

Pemilihan sistem yang akan digunakan dari kedua metode ini yang masih menjadi permasalahan dalam rencana penambangan tahunan di PT ABC. Pertimbangan akan dilihat dari sisi benefit operasional yang akan didapatkan.

\subsection{Rumusan Masalah}

Penelitian ini dilakukan karena adanya permasalahan dalam penentuan metode penanganan lumpur di sump. Pemilihan sistem yang akan digunakan mengacu kepada pembiayaan operasional yang lebih menguntungkan untuk dilakukan di sump Pit $\mathrm{Z}$ PT ABC.

\subsection{Batasan Masalah}

Batasan masalah dalam penelitian ini adalah penulis hanya membandingkan diantara dua metode, yaitu load and haul dan mud pumping pada perencanaan tahun 2020 di sump Pit Z PT ABC.

\subsection{Tujuan Penelitian}

Tujuan dari penelitian ini adalah :
1. Menghitung curah hujan harian berdasarkan data curah hujan beberapa tahun sebelumnya.

2. Menghitung debit air yang masuk ke dalam sump berdasarkan curah hujan rencana yang teah dihitung sebelumnya, dan luas area tangkapan hujan.

3. Menghitung volume lumpur aktual yang terdapat di sump Pit $\mathrm{Z}$.

4. Menentukan kebutuhan dan biaya pompa lumpur untuk mine dewatering agar sesuai rencana penambangan kuarter berikutnya.

5. Menganalisa biaya yang dibutuhkan untuk kegiatan load and haul lumpur yang terdapat di sump Pit $\mathrm{Z}$

6. Membandingkan biaya antara metode mud pumping dengan metode load and haul lumpur.

\subsection{Manfaat Penelitian}

Manfaat dari penelitian ini adalah

1. Dapat mengetahui gambaran atau prediksi curah hujan yang akan datang.

2. Mengetahui seberapa besar debit air yang masuk dalam kurun waktu tertentu dan luas daerah tangkapan hujan pada sump pit $\mathrm{Z}$.

3. Mengetahui berapa volume lumpur aktual yang ada di sump dan berada pada elevasi berapa.

4. Mampu menentukan jumlah dan jenis pompa dan pipa yang ideal untuk kebutuhan di sump pit Z.

5. Mengetahui besaran biaya yang dibutuhkan jika menggunakan metode load and haul untuk menangani lumpur yang terdapat di sump pit $\mathrm{Z}$.

6. Mengetahui metode mana yang lebih menguntungkan untuk diterapkan.

\section{METODOLOGI PENELITIAN}

Penelitian ini dilakukan pada Mei s.d. Juni 2020 dengan lokasi penelitian di PT ABC.

\subsection{Jenis Penelitian}

Metode penelitian yang digunakan adalah metode penelitian kuantitatif. Penelitian tipe kuantitatif dapat digunakan apabila data 
yang dikumpukan berupa data kuantitatif atau jenis data lain yang dapat dikuantitaskan dan diolah menggunakan teknik statistik.

Selain menggunakan metode penelitian kuantitatif pada penelitian ini juga digunakan metode penelitian terapan. Penelitian terapan lebih menekankan pada penerapan ilmu dan aplikasi ataupun penggunaan ilmu untuk keperluan tertentu.

\subsection{Teknik Pengumpulan Data}

Tahap pengumpulan data dimulai dengan studi literatur, yaitu mempelajari datadata perusahaan. Selanjutnya observasi lapangan berupa pengamatan secara langsung terhadap hal-hal yang akan dikaji.

\subsection{Teknik Analisis Data}

Teknik analisis data yang dilakukan adalah dengan menggabungkan teori dan datadata lapangan sehingga dari keduanya didapat pendekatan penyelesaian masalah.

\subsubsection{Pengambilan Data}

Tahap pengumpulan data dimulai dengan mengambil data primer berupa elevasi titik tertinggi, elevasi pipa buang dan pipa hisap, penentuan luas catchment area, debit air limpasan, debit airtanah dan jarak lintasan angkut. Data sekunder berupa face position Mei 2020 s.d. Desember 2020, data curah hujan, spesifikasi pompa, panjang dan diameter pipa, spesifikasi unit load and haul, rencana jam kerja dan billing rate masingmasing unit.

\subsubsection{Analisis Hasil Pengolahan Data}

Dilakukan secara kualitatif dan kuantitatif untuk memperoleh kesimpulan sementara. Selanjutnya kesimpulan sementara akan diolah lebih lanjut dalam bagian pembahasan. Pengolahan data dilakukan dengan melakukan simulasi beberapa opsi. Selanjutnya disajikan dalam bentuk tabel, kurva atau rangkaian perhitungan dalam penyelesaian masalah yang ada. Data-data yang diperoleh nantinya akan menjadi acuan dalam penentuan sistem apa yang akan digunakan.

\subsubsection{Kesimpulan}

Kesimpulan diambil dari hasil pengolahan data dengan membandingkan dan menganalisa opsi-opsi dan selanjutnya memberikan rekomendasi yang mendasar pada perusahaan.

\section{HASIL DAN PEMBAHASAN \\ 3.1 Analisis Kondisi Aktual \\ 3.1.1 Analisis Data Curah Hujan}

Dalam penelitian ini pengolahan data curah hujan dilakukan untuk mendapatkan besarnya nilai curah hujan dan intensitas hujan. Data curah hujan yang digunakan di daerah penelitian adalah selama 3 tahun mulai tahun 2017-2020 dengan periode ulang hujan 2 tahun. Perhitungan analisis curah hujan dilakukan dengan metode Gumbel. Berdasarkan perhitungan didapatkan data proyeksi curah hujan rata-rata dan maksimum untuk setiap bulan di tahun 2020 .

Tabel 3.1 Proyeksi Curah Hujan Tahun 2020

\begin{tabular}{|c|c|c|c|c|c|c|c|}
\hline Data analysis & $\begin{array}{l}\text { Periode Ulang } \\
\text { Hujan }\end{array}$ & $\begin{array}{c}\dot{X} \text { (average } \\
\text { actual rain } \\
\text { fall) }\end{array}$ & $\begin{array}{l}s \text { (standar } \\
\text { deviation) }\end{array}$ & Ỳm & Sm & $\begin{array}{l}\dot{X} \text { (average } \\
\text { rain fall) }\end{array}$ & $\begin{array}{l}\text { Xt (max daily } \\
\text { rain fall) }\end{array}$ \\
\hline Jan-20 & \multirow{12}{*}{2} & 10.78 & 1.09 & \multirow{12}{*}{0.40} & \multirow{12}{*}{0.70} & 12.34 & 51.00 \\
\hline Feb-20 & & 11.24 & 0.76 & & & 12.92 & 57.50 \\
\hline Mar-20 & & 12.10 & 4.12 & & & 13.49 & 185.00 \\
\hline Apr-20 & & 10.07 & 0.82 & & & 11.69 & 74.00 \\
\hline May-20 & & 5.59 & 2.32 & & & 7.07 & 52.00 \\
\hline Jun-20 & & 4.55 & 0.76 & & & 6.18 & 36.00 \\
\hline Jul-20 & & 4.40 & 4.38 & & & 5.78 & 45.00 \\
\hline Aug-20 & & 3.73 & 2.43 & & & 5.22 & 40.00 \\
\hline Sep-20 & & 2.03 & 1.67 & & & 3.61 & 37.00 \\
\hline Oct-20 & & 3.82 & 0.89 & & & 5.39 & 22.00 \\
\hline Nov-20 & & 21.27 & 2.97 & & & 22.77 & 136.00 \\
\hline Dec-20 & & 8.24 & 0.54 & & & 9.82 & 79.00 \\
\hline
\end{tabular}

\subsubsection{Daerah Tangkapan Hujan dan Debit} Air Limpasan

Penentuan luasan daerah tangkapan hujan didasarkan oleh topografi daerah tangkapan, rencana penambangan setahun, dan arah aliran air permukaan. Air limpasan adalah bagian dari curah hujan yang mengalir diatas permukaan tanah menuju titik terendah. Air limpasan berlangsung ketika jumlah curah hujan melebihi laju infiltrasi air ke dalam tanah. Debit air limpasan dihitung dengan menggunakan persamaan sebagai berikut:

$$
\mathrm{Q}=0,278 \times \mathrm{C} \times \mathrm{I} \times \mathrm{A}
$$

Contoh perhitungan debit air limpasan permukaan rata-rata pada bulan May 2020 sebagai berikut:

$$
\mathrm{Q}=0,278 \times \mathrm{C} \times \mathrm{I} \times \mathrm{A}_{\text {avg }}
$$


$\mathrm{Q}=0,278 \times 0,7 \times 2,05 \mathrm{~mm} /$ hours $\times 24$ hours/day X $2,08 \quad \mathrm{~km}^{2} \quad$ X $\quad 1.000$ $\mathrm{m} . \mathrm{m}^{2} / \mathrm{mm} \cdot \mathrm{km}^{2}$

$\mathrm{Q}=19,939 \mathrm{~m}^{3} /$ day

Contoh perhitungan debit air limpasan permukaan maksimum pada bulan May 2020 adalah sebagai berikut:

$$
\begin{aligned}
& \mathrm{Q}=0,278 \times \mathrm{C} \times \mathrm{I} \times \mathrm{A}_{\max } \\
& \mathrm{Q}=0,278 \quad \mathrm{x} \quad 0,7 \quad \mathrm{x} \quad 3,9 \mathrm{~mm} / \text { hours } \mathrm{x} \quad 24 \\
& \text { hours/day } \quad \mathrm{x} \quad 2,08 \quad \mathrm{~km}^{2} \quad \mathrm{x} \quad 1.000 \\
& \mathrm{~m} . \mathrm{m}^{2} / \mathrm{mm} \cdot \mathrm{km}^{2} \\
& \mathrm{Q}=54,137 \mathrm{~m}^{3} / \text { day }
\end{aligned}
$$

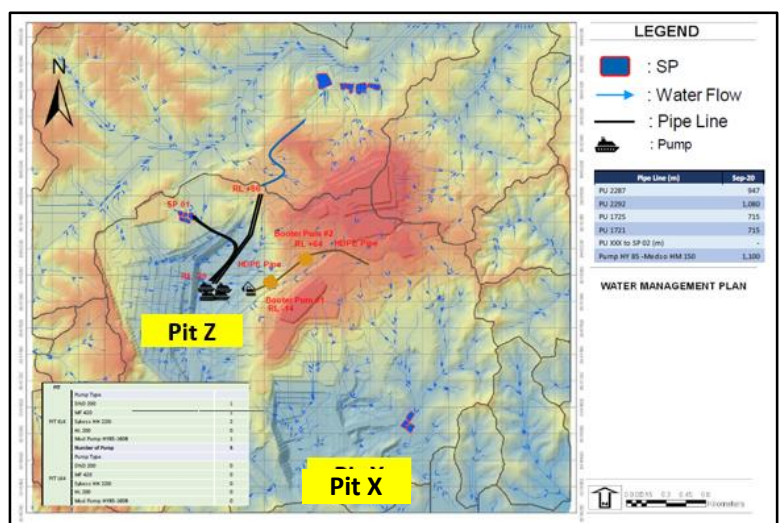

Gambar 3.1 Peta Daerah Tangkapan Hujan dan Stream Flow

Debit air limpasan permukaan pada bulan Januari hingga Desember 2020 pada Pit $\mathrm{Z}$ dapat dilihat pada tabel 3.2.

Tabel 3.2 Debit Air Limpasan Tahun 2020

\begin{tabular}{|c|c|c|c|}
\hline Item/Month & CA (km2) & $\begin{array}{c}\text { Water ingress } \\
\text { (m3/day) with } \\
\text { rainfall average }\end{array}$ & $\begin{array}{c}\text { Water ingress } \\
\text { (m3/day) with } \\
\text { rainfall max }\end{array}$ \\
\hline Jan-20 & 1.97 & 16,718 & 34,679 \\
\hline Feb-20 & 1.96 & 20,082 & 44,024 \\
\hline Mar-20 & 1.96 & 21,015 & 124,065 \\
\hline Apr-20 & 2.06 & 22,004 & 70,778 \\
\hline May-20 & 2.08 & 19,939 & 54,137 \\
\hline Jun-20 & 2.10 & 12,973 & 34,012 \\
\hline Jul-20 & 1.99 & 17,331 & 41,928 \\
\hline Aug-20 & 1.97 & 15,890 & 39,471 \\
\hline Sep-20 & 1.99 & 15,698 & 57,190 \\
\hline Oct-20 & 2.03 & 18,076 & 14,176 \\
\hline Nov-20 & 2.04 & 39,951 & 127,661 \\
\hline Dec-20 & 1.72 & 17,241 & 69,047 \\
\hline
\end{tabular}

\subsubsection{Perhitungan Penambahan Lumpur pada Sump Pit $\mathrm{Z}$}

Volume lumpur di sump diasumsikan sebesar $30 \%$ dari total volume water ingress average. Dengan anggapan bahwa setiap air yang masuk ke sump $30 \%$ persen dari volumenya adalah material yang tererosi ketika air limpasan melaju di atas permukaan tanah.

Debit air limpasan per hari yang masuk ke sump Pit $\mathrm{Z}$ dikalikan 30 hari, untuk mendapatkan total volume sump dalam 1 bulan.

Total vol air per bulan $=$ Water ingress/day $\mathrm{x}$ 30 days

Total vol air perbulan $=16,718 \mathrm{~m}^{3} /$ day $\times 30$ days

Total vol air perbulan $=16,718 \mathrm{~m}^{3} /$ day $\times 30$ days

Total vol air perbulan $=598,182 \mathrm{~m}^{3}$

Volume lumpur yang terdapat di sump Pit $\mathrm{Z}$ pada setiap bulan di tahun 2020 sebagai berikut:

Tabel 3.3 Total Volume Lumpur di Sump Pit Z Tahun 2020

\begin{tabular}{|c|c|c|}
\hline Item/Month & Total Water (m3) & Total Mud (m3) \\
\hline Jan-20 & 501,532 & 150,460 \\
\hline Feb-20 & 602,447 & 180,734 \\
\hline Mar-20 & 630,435 & 189,131 \\
\hline Apr-20 & 660,122 & 198,036 \\
\hline May-20 & 598,183 & 179,455 \\
\hline Jun-20 & 389,190 & 147,412 \\
\hline Jul-20 & 519,944 & 159,395 \\
\hline Aug-20 & 476,708 & 153,608 \\
\hline Sep-20 & 470,945 & 146,091 \\
\hline Oct-20 & 542,271 & 164,772 \\
\hline Nov-20 & $1,198,529$ & 375,531 \\
\hline Dec-20 & 517,215 & 386,696 \\
\hline
\end{tabular}

\subsection{Analisis Penanganan Lumpur dengan Metode Pemompaan}

\subsubsection{Analisis Head dan Debit Pompa}

Sistem penanganan lumpur tambang menggunakan metode pemompaan dengan pompa lumpur merupakan kombinasi antara submersible pump dan slurry booster. Perhitungan head dari konfigurasi tersebut berbeda-beda. Total head hingga Desember 2020 pada sump Pit $\mathrm{Z}$ adalah 132 meter. 
Tabel 3.4 Total Head dalam Meter

\begin{tabular}{|c|c|c|c|c|c|c|}
\hline Item $(\mathbf{m})$ & Top Elevation & $\begin{array}{c}\text { Bottom } \\
\text { Elevation }\end{array}$ & Static Head & Friction Lost & $\begin{array}{c}\text { NPSHR }+ \\
\text { NPSHA }\end{array}$ & Total Head \\
\hline May-20 & 85 & -10 & 95 & 12 & 6 & 113 \\
\hline Jun-20 & 85 & -10 & 95 & 12 & 6 & 113 \\
\hline Jul-20 & 85 & -20 & 105 & 12 & 6 & 123 \\
\hline Aug-20 & 85 & -29 & 114 & 12 & 6 & 132 \\
\hline Sep-20 & 85 & -29 & 114 & 12 & 6 & 132 \\
\hline Oct-20 & 85 & -29 & 114 & 12 & 6 & 132 \\
\hline Nov-20 & 85 & -29 & 114 & 12 & 6 & 132 \\
\hline Dec-20 & 85 & -29 & 114 & 12 & 6 & 132 \\
\hline
\end{tabular}

Estimasi debit pompa dilakukan setelah total head pompa diketahui. Nilai total head pompa telah di-plot ke dalam kurva spesifikasi pompa dan dipotongkan dengan efisiensi tertentu sehingga diperoleh debit yang sesuai dengan total head pompa.

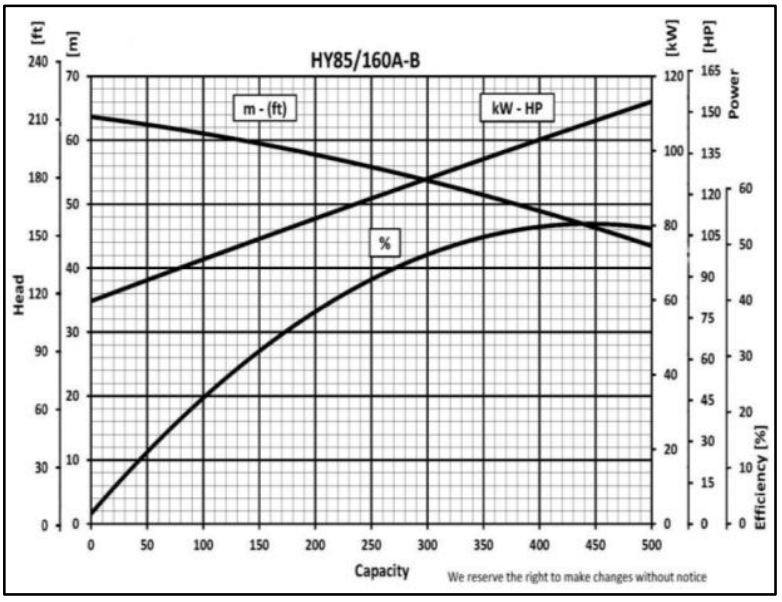

Gambar 3.2 Kurva Karakteristik Pompa

Untuk meningkatkan kapasitas pemompaan, maka dibatasi sampai dengan efisiensi maksimal. Jika dipaksakan melebihi kapasitas normal (kapasitas spesifikasi) dengan nilai head total lebih besar dari head maksimal, maka akan berpengaruh pada tingkat keausan pompa.

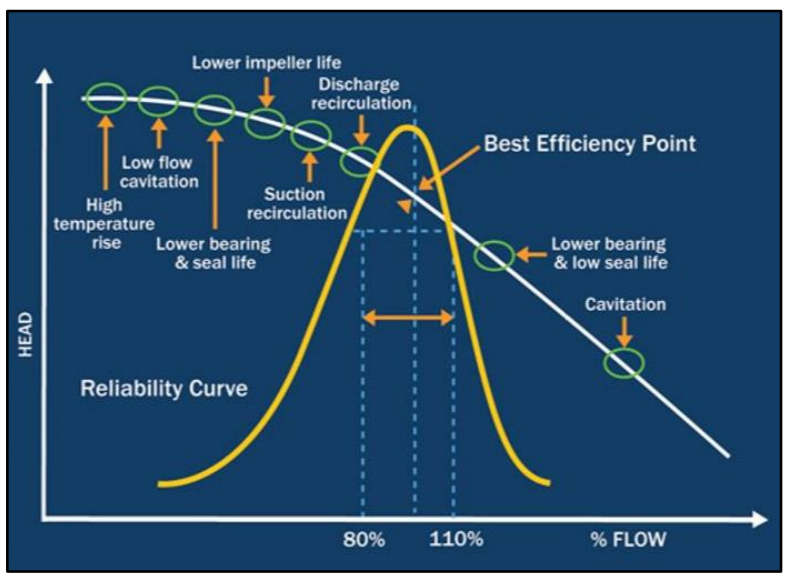

Gambar 3.3 Kurva Reliability Pompa
Pengaruh nilai RPM (kecepatan pompa), head dan kapasitas yang melebihi keadaan normal akan menghasilkan getaran yang akan mengakibatkan kerusakan pada komponen pompa, menimbulkan suara yang bising, casing pompa cepat panas dan boros dalam pemakaian bahan bakar.

\subsubsection{Perhitungan Kebutuhan Pipa HDPE}

Instalasi pemipaan pada sump pit $\mathrm{Z}$ menggunakan pipa HDPE (high density polyetylene). Untuk tipe, ukuran dan panjang pipa yang digunakan pada instalasi pemipaan dapat dilihat pada tebael 3.5.

Tabel 3.5 Kebutuhan dan Tipe Pipa

\begin{tabular}{|c|c|c|c|c|c|c|}
\hline Item & $\begin{array}{c}\text { Submersible } \\
\text { Pump }(\mathrm{m})\end{array}$ & $\begin{array}{c}\text { Booster } 1 \\
(\mathrm{~m})\end{array}$ & $\begin{array}{c}\text { Booster } 2 \\
(\mathrm{~m})\end{array}$ & $\begin{array}{c}\text { Total Pipa } \\
(\mathrm{m})\end{array}$ & $\begin{array}{c}\text { Diameter } \\
(\mathrm{mm})\end{array}$ & Tipe Pipa \\
\hline May-20 & 100 & 750 & 250 & 1,100 & 280 & Pn10 \\
\hline Jun-20 & 100 & 750 & 250 & 1,100 & 280 & Pn10 \\
\hline Jul-20 & 100 & 850 & 250 & 1,200 & 280 & Pn10 \\
\hline Aug-20 & 100 & 500 & 600 & 1,200 & 280 & Pn10 \\
\hline Sep-20 & 100 & 500 & 600 & 1,200 & 280 & Pn10 \\
\hline Oct-20 & 100 & 500 & 600 & 1,200 & 280 & Pn10 \\
\hline Nov-20 & 100 & 500 & 600 & 1,200 & 280 & Pn10 \\
\hline Dec-20 & 100 & 500 & 600 & 1,200 & 280 & Pn10 \\
\hline
\end{tabular}

\subsubsection{Perhitungan Kebutuhan Pompa Lumpur di Sump Pit $\mathrm{Z}$}

Dari hasil analisa total head, maka dapat ditentukan spesifikasi pompa yang sesuai untuk pemompaan lumpur pada sump Pit Z. Agar tercapainya target dewatering pada akhir tahun, maka dengan data debit yang didapat dari grafik pompa dapat ditentukan berapa jumlah pompa yang dibutuhkan.

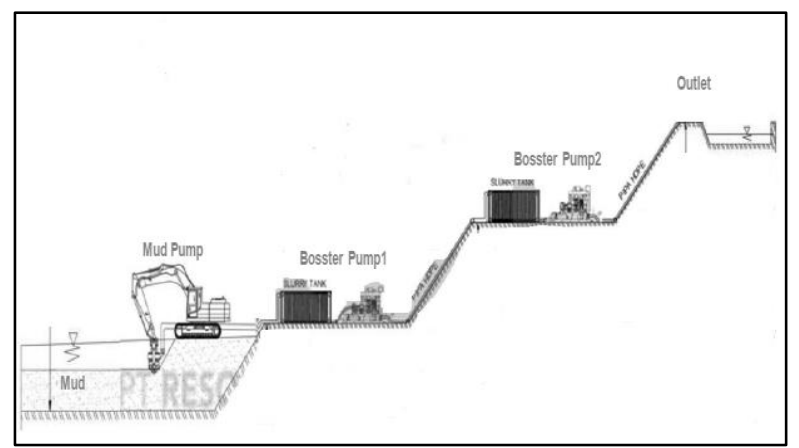

Gambar 3.4 Scenario Pompa Lumpur

Total head ideal untuk submersible pump adalah 20 meter, sedangkan untuk slurry booster adalah maksimal 83 meter. Sehingga konfigurasi yang tepat untuk pemompaan 
lumpur di sump pit $\mathrm{Z}$ adalah 1 x submersible pump dan 2 x slurry booster.

Pemilihan pompa lumpur juga harus memperhatikan SG aktual di lapangan. Perhitungan SG di lapangan dilakukan dengan menimbang massa (gram) 1 liter lumpur menggunakan timbangan. Massa yang didapatkan dibagi dengan $1000 \mathrm{ml}$.

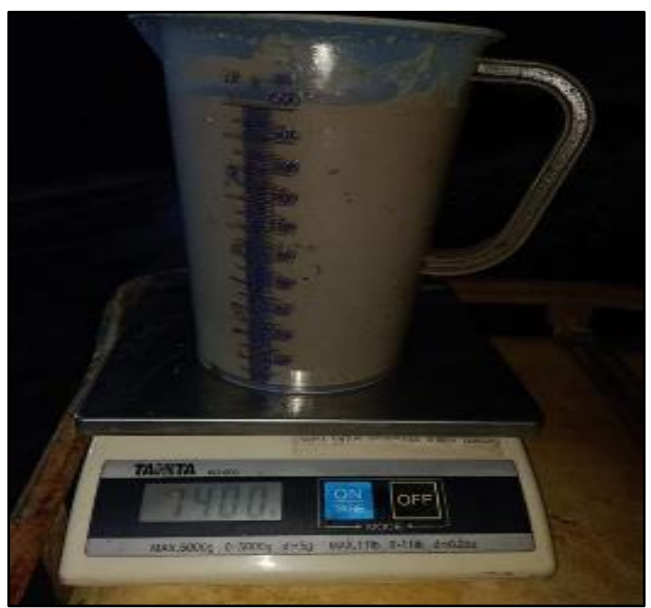

Gambar 3.5 Perhitungan SG Sump Pit Z

Berdasarkan pertimbangan tersebut, maka spesifikasi submersible pump yang sesuai adalah Dragflow HY85-160B dan slurry booster yang sesuai adalah Metso HM150. Pompa tersebut dapat menerima input $S G$ sebesar 1,3 s.d.1,4.

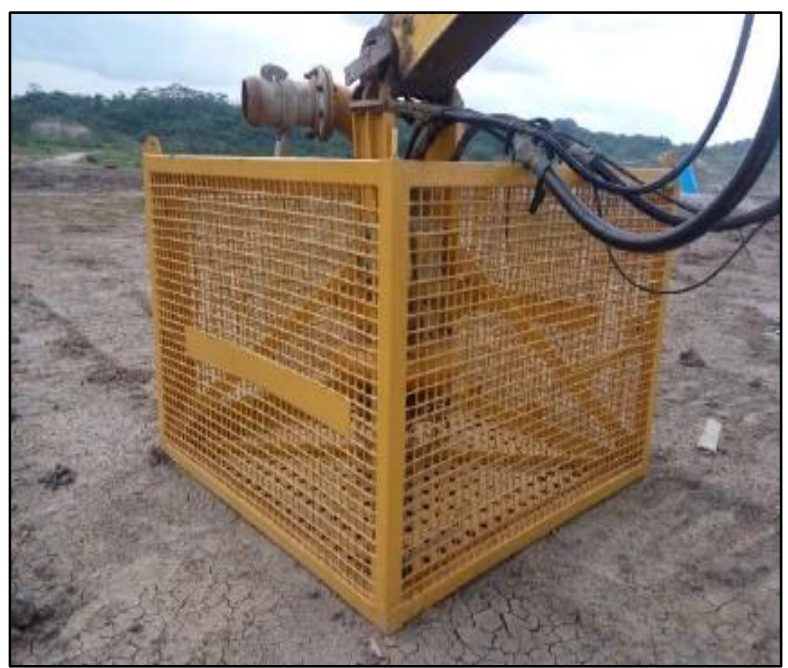

Gambar 3.6 Dragflow HY85-160B

Hasil perhitungan kebutuhan pompa dengan kriteria di atas dapat dilihat pada tabel 3.6 .
Tabel 3.6 Konfigurasi Pompa

\begin{tabular}{|c|c|c|c|c|c|c|c|c|c|}
\hline \multirow{2}{*}{$\begin{array}{l}\text { Item / } \\
\text { Month }\end{array}$} & \multicolumn{3}{|c|}{ Mud Pump HY85-160B } & \multicolumn{3}{c|}{ Transfer Pump Medso 150} & \multicolumn{3}{c|}{ Transfer Pump Medso 150} \\
\cline { 2 - 11 } & Top RL & Bottom RL & $\begin{array}{c}\text { Static } \\
\text { Head (m) }\end{array}$ & Top RL & Bottom RL & $\begin{array}{c}\text { Static } \\
\text { Head (m) }\end{array}$ & Top RL & Bottom RL & $\begin{array}{c}\text { Static } \\
\text { Head (m) }\end{array}$ \\
\hline May-20 & 5 & -10 & 15 & 66 & 5 & 61 & 86 & 66 & 20 \\
\hline Jun-20 & 5 & -10 & 15 & 66 & 5 & 61 & 86 & 66 & 20 \\
\hline Jul-20 & -10 & -20 & 10 & 66 & -10 & 76 & 86 & 66 & 20 \\
\hline Aug-20 & -14 & -29 & 15 & 64 & -14 & 78 & 105 & 66 & 39 \\
\hline Sep-20 & -14 & -29 & 15 & 64 & -14 & 78 & 105 & 66 & 39 \\
\hline Oct-20 & -14 & -29 & 15 & 64 & -14 & 78 & 105 & 66 & 39 \\
\hline Nov-20 & -14 & -29 & 15 & 64 & -14 & 78 & 105 & 66 & 39 \\
\hline Dec-20 & -14 & -29 & 15 & 64 & -14 & 78 & 105 & 66 & 39 \\
\hline
\end{tabular}

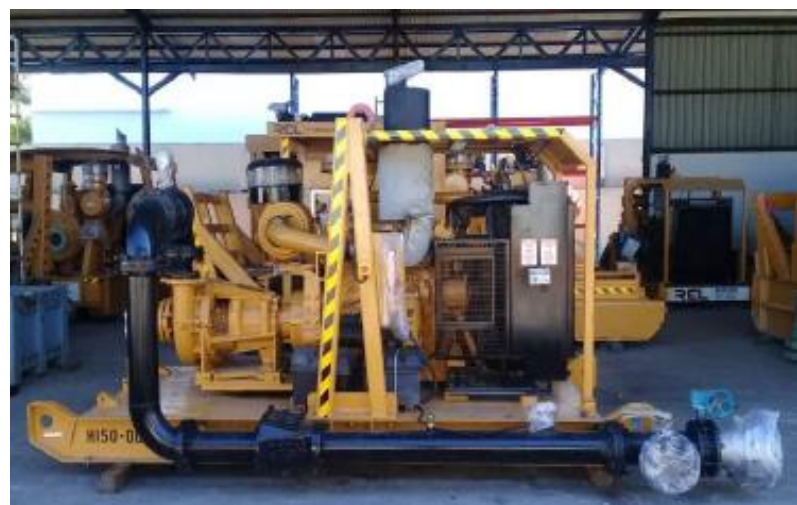

Gambar 3.7 Slurry Booster Metso HM150

\subsubsection{Perhitungan Biaya Kebutuhan Pompa Lumpur}

Dari analisis kebutuhan pompa, maka biaya yang akan dikeluarkan untuk pengoperasian pompa lumpur sesuai konfigurasi tersebut seperti pada tebel 3.7.

Tabel 3.7 Total Biaya Penanganan Lumpur dengan Metode Pemompaan

\begin{tabular}{|c|c|c|c|c|c|c|c|c|}
\hline \multirow{2}{*}{\multicolumn{2}{|c|}{ Item/Month }} & \multicolumn{7}{|c|}{ Mud Pump (PT REL) } \\
\hline & & \multicolumn{4}{|c|}{ HY85 to Metso HM 150} & \multicolumn{3}{|c|}{ Support Mud Pump } \\
\hline \multicolumn{2}{|c|}{ Unit } & $\begin{array}{c}\text { Toal } \\
\text { Cost/month }\end{array}$ & $\begin{array}{l}\text { Hose }(m)- \\
\text { Layilat }\end{array}$ & Hose $1(\mathrm{~m})$ & Hose $2(m)$ & EX-350 & $\begin{array}{l}\text { Komatsu } \\
\text { D85EsS }\end{array}$ & $\begin{array}{c}\text { Hitachi } \\
\text { ZK210LC.5G }\end{array}$ \\
\hline \multicolumn{2}{|c|}{ Billing Rate $(\$ / \mathrm{hr})$} & $\$ 52,816.90$ & \multirow{2}{*}{ Max length } & \multirow{2}{*}{ Max length } & \multirow{2}{*}{ Max length } & 30.68 & 52.17 & 36.85 \\
\hline & & 1 & & & & 1 & 1 & 1 \\
\hline \multirow{2}{*}{ May-20 } & WH & \multirow{2}{*}{$\$ 52,816.90$} & \multirow{2}{*}{100} & \multirow{2}{*}{750} & \multirow{2}{*}{250} & 496 & 347 & 347 \\
\hline & Operating cost & & & & & $\$ 15,217.28$ & \$18,113.42 & $\$ 12,794.32$ \\
\hline \multirow{2}{*}{ Jun-20 } & WH & \multirow{2}{*}{$\$ 52,816.90$} & \multirow{2}{*}{100} & \multirow{2}{*}{750} & \multirow{2}{*}{250} & 480 & 336 & 336 \\
\hline & Operating cost & & & & & $\$ 14,726.40$ & $\$ 17,529.12$ & $\$ 12,381.60$ \\
\hline \multirow{2}{*}{ Jul-20 } & WH & \multirow{2}{*}{$\$ 52,816.90$} & \multirow{2}{*}{100} & \multirow{2}{*}{850} & \multirow{2}{*}{250} & 496 & 347 & 347 \\
\hline & Operating cost & & & & & $\$ 15,217.28$ & $\$ 18,113.42$ & $\$ 12,794.32$ \\
\hline \multirow{2}{*}{ Aug-20 } & WH & \multirow{2}{*}{$\$ 52,816.90$} & \multirow{2}{*}{100} & \multirow{2}{*}{500} & \multirow{2}{*}{600} & 496 & 347 & 347 \\
\hline & Operating cost & & & & & $\$ 15,217.28$ & $\$ 18,113.42$ & $\$ 12,794.32$ \\
\hline \multirow{2}{*}{ Sep-20 } & WH & \multirow{2}{*}{ \$ 52,816.90 } & \multirow{2}{*}{100} & \multirow{2}{*}{500} & & 480 & 336 & 336 \\
\hline & Operating cost & & & & & $\$ 14,726.40$ & $\$ 17,529.12$ & $\$ 12,381.60$ \\
\hline $0+20$ & WH & 55288690 & 100 & 500 & 600 & 496 & 347 & 347 \\
\hline & Operating cost & \$ $32,816.90$ & 100 & & & $\$ 15,217.28$ & $\$ 18,113.42$ & $\$ 12,794.32$ \\
\hline Nov-20 & WH & 55281690 & 100 & 500 & 600 & 480 & 336 & 336 \\
\hline Nov- 20 & Operating cost & > $32,810.90$ & 100 & & & $\$ 14,726.40$ & $\$ 17,529.12$ & $\$ 12,381.60$ \\
\hline Dec-20 & WH & $\$ 5288690$ & 100 & 500 & 600 & 496 & 347 & 347 \\
\hline Dec-20 & Operating cost & > $\$ 2,810.90$ & 100 & 500 & & $\$ 15,217.28$ & \$ 18,113.42 & $\$ 12,794.32$ \\
\hline & $\operatorname{lng} \cos (\$ s)$ & $\$ 422,535.21$ & & $\$ 25,150.91$ & $\$ 30,181.09$ & $\$ 120,265.60$ & $\$ 143,154,48$ & $\$ 101,116,40$ \\
\hline & & $\$$ & & & & & & $842,403.68$ \\
\hline
\end{tabular}

Total biaya yang dibutuhkan untuk penanganan lumpur dengan pengoperasian 
pompa lumpur di bulan Mei 2020 s.d. Desember 2020 sebesar \$ 842,403.

\subsection{Analisis Penanganan Lumpur dengan Metode Load and Haul}

Sistem penanganan lumpur tambang menggunakan metode load and haul merupakan kombinasi alat-alat mekanis seperti alat gali-muat, alat angkut dan alat support. Kombinasi yang digunakan antara lain 1 unit Excavator Liebherr 984 sebagai alat galimuat, 3 unit Cat 777D dengan penambahan tail gate pada vessel sebagai alat angkut, 1 unit bulldozer D65P sebagai pendorong lumpur, 1 unit Excavator Hitachi 350 dan 1 unit motor grader Cat 14-M sebagai support di sepanjang lintasan angkut dan 1 unit bulldozer Cat D8R sebagai support di out pit dump.

Parameter yang digunakan dalam perhitungan operating cost penanganan lumpur menggunakan metode load and haul antara lain billing rate $(\$ / \mathrm{hr})$ dan working hours. Total volume lumpur dalam perhitungan tersebut adalah sama dengan total volume yang akan dipompa sehingga perbandingan cost dari kedua sistem tersebut ekuivalen.

Tabel 3.8 Kombinasi Alat Mekanis untuk Penanganan Lumpur Tambang

\begin{tabular}{|c|c|c|c|c|}
\hline \multicolumn{2}{|c|}{ Item/Month } & Unit & $\begin{array}{l}\text { Total } \\
\text { Unit }\end{array}$ & $\begin{array}{c}\text { Pdty } \\
\text { (bcm/hr) }\end{array}$ \\
\hline \multirow{6}{*}{$\begin{array}{c}\text { Load \& } \\
\text { Haul }\end{array}$} & \multirow{2}{*}{ Loading Mud } & EX 984 & 1 & 250 \\
\hline & & D65-P & 1 & 137 \\
\hline & \multirow{3}{*}{ Hauling Mud } & CAT-777 & 3 & 110 \\
\hline & & Cat - 14M & 1 & 38 \\
\hline & & EX-350 & 1 & 100 \\
\hline & Dumping & Cat D8R & 1 & 269 \\
\hline
\end{tabular}

Tabel 3.9 Total Biaya Penanganan Lumpur dengan Metode Load and Haul

\begin{tabular}{|c|c|c|c|c|c|c|c|}
\hline \multirow{2}{*}{ Item } & \multicolumn{2}{|c|}{ Loading Mud } & \multicolumn{3}{|c|}{ Hauling Mud } & \multirow{2}{*}{$\begin{array}{l}\text { Dumping } \\
\text { Cat D8R }\end{array}$} & \multirow{2}{*}{\begin{tabular}{|c|} 
Total Operating \\
Cost (\$)
\end{tabular}} \\
\hline & EX 984 & D65-P & CAT-777 & Cat $-14 \mathrm{M}$ & EX-350 & & \\
\hline May-20 & 62,073 & 12,523 & 141,076 & 8,945 & 5,367 & 11,628 & 241,612 \\
\hline Jun-20 & 1 & 661 & 5,525 & 6,472 & 3,883 & 8,414 & 1,427 \\
\hline Jul-2 & & 756 & & & & 916 & 51 \\
\hline Aug-20 & 62,073 & 9,960 & 1,076 & 9,9 & 9,960 & 9,960 & 242,988 \\
\hline Sep-20 & & 02 & & & 2 & 173 & 30 \\
\hline Oct-20 & 62,07 & 5,080 & 76 & 9 & 2,177 & 4,717 & 18,753 \\
\hline Nov-20 & 60,071 &, 603 & 6,525 & 4,002 & 14,401 & 1,202 & 299,804 \\
\hline Dec-2 & , & 19,732 & & 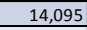 & & 18,323 & 263,756 \\
\hline Total & 490,580 & 110,517 & $1,114,955$ & 81,786 & 53,055 & 103,334 & $1,954,227$ \\
\hline
\end{tabular}

Total biaya yang dibutuhkan untuk penanganan lumpur dengan métode load and haul di bulan Mei 2020 s.d. Desember 2020 sebesar \$ 1,954,227.

\section{KESIMPULAN DAN SARAN}

\subsection{Kesimpulan}

Dari pembahasan tersebut, maka kesimpulan dari penelitian ini, yaitu :

1. Curah hujan harian maksimum pada bulan Juli adalah $45 \mathrm{~mm}$.

2. Debit air limpasan yang masuk ke sump pit $\mathrm{Z}$ sebesar $17,331 \mathrm{~m}^{3} /$ hari, dengan luas daerah tangkapan hujan (catchment area) pada sump pit $\mathrm{Z}$ sebesar $1.99 \mathrm{~km}^{2}$.

3. Volume lumpur aktual yang terdapat di sump pit $\mathrm{Z}$ pada bulan Juni $2020 \mathrm{~h}$ sebesar $147,412 \mathrm{~m}^{3}$.

4. Dari hasil perhitungan kebutuhan pompa lumpur untuk menangani lumpur pada sump pit $\mathrm{Z}$ sebesar $\$ 842,403$.

5. Jika menggunakan metode load and haul, besar total biaya yang dibutuhkan adalah \$ $1,954,227$.

6. Berdasarkan hasil perhitungan biaya dari kedua metode tersebut, sehingga dapat ditentukan bahwa metode mud pumping lebih menguntungkan daripada metode load and haul dengan penghematan mencapai $57 \%$.

\section{DAFTAR PUSTAKA}

Gautama., RS.. 1999. Sistem Penyaliran Tambang. Institut Teknologi Bandung.

PT KSB Indonesia. 2017. Spesifikasi Poma DND 200 dan Grafik RPM

Suwandhi, A.. 2004. Perencanaan Sistem Penyaliran Tambang. Universitas Islam Bandung.

A. Muri Yusuf. 2005. Metodologi Penelitian. UNP Press: Padang.

R. Siahan, dkk. 2017. Evaluasi Teknis Sistem Penyaliran Tambang Studi Kasus: PT Bara Energi Lestari Kbupaten Nagan Rsya Aceh. Jurnal Ilmiah Mahasiswa Teknik Kebumian. 
P-ISSN: 2089-5925 E-ISSN: 2621-9328

Antrant

Jurnal Teknik Patra Akademika

PATA

Arademika

Volume 11 No. 01 Juli 2020 